\title{
Frailty vs. Wise as Thematic Verbatim Perceptions of Aging from College Students Enrolled in a Health and Aging Course
}

\author{
Marybeth Groot, Elizabeth Orsega-Smith \\ Department of Behavioral Health \& Nutrition, University of Delaware, Newark, DE, USA \\ Email: eosmith@udel.edu
}

How to cite this paper: Groot, M., \& Orsega-Smith, E. (2020). Frailty vs. Wise as Thematic Verbatim Perceptions of Aging from College Students Enrolled in a Health and Aging Course. Creative Education, 11, 1231-1242.

https://doi.org/10.4236/ce.2020.118092

Received: July 13, 2020

Accepted: August 9, 2020

Published: August 12, 2020

Copyright $\odot 2020$ by author(s) and Scientific Research Publishing Inc. This work is licensed under the Creative Commons Attribution International License (CC BY 4.0).

http://creativecommons.org/licenses/by/4.0/

\begin{abstract}
The older adult population is rapidly growing expecting to reach nearly 95 million by 2060. Consequently, there is a growing need for young adults preparing to enter the workforce to have accurate perceptions of the aging process. The purpose of this study was to examine students' verbatim descriptors of someone over 65 years of age and how they change after completing an undergraduate health and aging course. 132 junior-level Health Behavior Science undergraduate students completed a pre-course and post-course questionnaire that assessed aging knowledge and perceptions. A thematic analysis was conducted to examine students' descriptors of individuals $65+$ pre- and post-course. An evaluation of the qualitative responses indicated that the undergraduate students' perceptions of older adults and aging changed from their pre-course to post course responses. Positive personality trait descriptors increased from 160 (11.5\%) initially to $268(31.8 \%)$ following course completion. Conversely, negative traits of being sedentary/inactive (pre $(4.6 \%)$ to post $(0.5 \%)$ ), being slow (pre $(4.8 \%)$ to post $(2.5 \%)$ ), having health problems (pre $(9.7 \%)$ to post $(4.5 \%)$ ), and being fragile (pre $(7.5 \%)$ to post $(5.3 \%)$ ) all decreased. Independent samples paired t test showed a significant increase $(p<0.0001)$ in aging knowledge scores from pre to post course. In year one, the scores increased from $64.45(+12.63)$ to 78.66 $(+12.67)$ and in year two the scores increased from $69.41(+13.12)$ to 80.75 $(+11.07)$. Overall, this study demonstrated that an undergraduate health and aging course with a service-learning component greatly impacted undergraduate students' perceptions of older adults and the aging process to be more positive.
\end{abstract}

\section{Keywords}

Aging Perceptions, College Students, Aging Process, Educational Course 


\section{Introduction}

The older adult population is rapidly growing and is expected to reach nearly 95 million by 2060 (Vespa, Armstrong, \& Medina, 2018). Consequently, there is a growing need for workers in the gerontology specialization. Employers and health and social service providers are becoming more dependent upon higher education to produce professionals trained in aging (Gellis, Sherman, \& Lawrance, 2003). It is critical that young adults have accurate perceptions of older adults and the aging process, as these perceptions significantly impact individual behavior, professional practices, and public policy (Sweetland, Volmert, \& O'Neil, 2017). However, research suggests that it is becoming increasingly difficult to recruit and train students for careers in gerontology due to common negative perceptions of older adults among the undergraduate student population (Gellis et al., 2003).

In fact, research has shown that the undergraduate student population seems to have a higher prevalence of stereotypical views of the older adult population when compared to other age groups (Cohen, Sandel, Thomas, \& Barton, 2004). It is common for students to stereotype older adults as being lonely, depressed, and isolated, and having dementia (Cohen, Sandel, Thomas, \& Barton, 2004). The current body of literature suggests that societal views of aging may greatly contribute to the negative perceptions that are formed in childhood and carried into adulthood (Bodner, 2009; Butler, 1980; Mendonca, Marques, \& Abrams, 2018). Happel and colleagues found that students perceived working with older adults as "boring, frustrating, depressing, and lacking diversity" (Happel \& Brooker, 2001). Similarly, aging is often associated with death and dying which makes many individuals anxious and uncomfortable, and therefore, avoidant of older adults (Feenstra, 2012; Henderson, Xiao, Siegloff, Kelton, \& Paterson, 2008).

Media generally portrays older adults as being disabled, dependent, incompetent, and senile, thus contributing to the feelings of dread and anxiety surrounding the aging process (Bodner, 2009; Fiske et al., 2002). Advertisements, television, music, and other various forms of entertainment have also significantly contributed to societal views of aging and older adults (Vickers, 2007; Wurtele, 2009). Often these portrayals are used in an attempt to sell a product while molding ageism-related attitudes, thus contributing to the negative perceptions of older adults and aging among undergraduate students and society as a whole (McHugh, 2003).

Evidence suggests that personal experiences with older adults greatly contribute to students' perceptions of older adults and aging by providing a much more accurate view of aging (O'Hanlon \& Brookover, 2002). Researchers have found that higher perceived quality of relationships with older adult family members is significantly associated with positive attitudes toward older adults, therefore, reducing negative perceptions of older adults (Obhi \& Woodhead, 2016). Similarly, positive interactions between children and older parents or 
grandchildren and grandparents may reduce negative perceptions of older adults and the aging process (Kimuna, Knox, \& Zusman, 2005). Thus, it appears as though meaningful interactions such as volunteering or service learning could reduce the prevalence of negative perceptions of older adults (Kalisch, Coughlin, Ballard, \& Lamson, 2013; Schwartz \& Simmons, 2001).

Unfortunately, developing positive perceptions of older adults may be increasingly difficult as many children do not have the opportunities they once had for continued contact with the elderly (Bales, Eklund, \& Siffin, 2000). Many adult children move away from their parents, thus making it difficult for their children to interact with their grandparents. This decreases the opportunity for children to form accurate perceptions of the older adult population (Bales et al., 2000; Newman, Ward, Smith, Wilson, \& McCrea, 1997). Therefore, it is a possibility that many individuals form their perceptions of older adults and aging based on what is portrayed in the media (McHugh, 2003).

In attempt to bridge the generation gap, intergenerational service-learning programs have been implemented across all levels of education to encourage meaningful interactions between the young and old in the community settings (Bales et al., 2000; Fair \& Delaplane, 2015). The current body of literature suggests that service-learning experiences provide students with a greater understanding of older adults and may decrease negative perceptions about older adults among the undergraduate student population (O'Hanlon \& Brookover, 2002). In order to break the chain of stereotypes for older adults, universities should further explore how courses on health and aging with an intergenerational service-learning component impact undergraduate students' perceptions of older adults and the aging process (Darling, 2016).

The existing body of literature tends to focus on undergraduate students' aging knowledge and attitudes toward older adults primarily utilizing a knowledge questionnaire. This study was unique because we analyzed undergraduate students' verbatim descriptions of adults aged 65 and over. The purpose of this study was to examine how undergraduate students' perceptions of aging change by taking an undergraduate health and aging course.

\section{Methods}

\subsection{Course Information}

Students enrolled in a 15-week Health and Aging course at a Mid-Atlantic University were participants in this project. Students were primarily junior level Health Behavior Science majors and this was a required course for their major. In this twice per week 75-minute course, students were exposed to the biological, psychological, and social aspects of aging through lectures, group projects, and hands-on projects.

The course objectives included that 1) through lectures students will define common terms found in the area of aging, identify the demographic trends of aging America, and evaluate how increasing numbers of older adults will impact 
health and physical activity related disciplines; 2) through group projects students will generate plans to increase the health and well-being of older adults, will outline some of the aging trends in today's society, will compile information on health-related services for older adults; and 3) through hands-on projects students will engage in activities with older adults and gain a brief insight into the lives of older adults.

Some examples of class assignments completed outside of the classroom include: having a decreased sensory experience to mimic age-related changes, attending and participating in an exercise class for older adults, creating an aging plan for themselves across the decades, create a Blue Zones plan, and participate in a 2 - 3 hour mini service-learning experience at a senior center or assisted living facility.

Some examples of in-class assignments included, investigating natural and herbal supplements that older adults frequently take, exploring the students' hometown in terms of demographics specifically looking at the number of people 65 and older, the walkability of the area and the housing available for older adults, completing a longevity calculator, examining a retirement calculator, and experiencing stages of Alzheimer's disease through role plays.

In addition, three initiates were embarked upon for a two-year period. Senior center directors provided the students with virtual tours of their locations. In this case, it was interactive in that students were able to ask questions about the specific sites with live answers being provided. This allowed students to tour a center from their classroom while eliminating the barriers of physically traveling to the site.

The second piece was that students interacted directly with the older adults via iPad technology through the internet. Older adults were connected directly with the BHAN 335 class members via internet connection using iPads. The class followed an older adult on a weekly basis in a live setting through the use of an internet video conference platform. Initially, the older adult was in the senior center and was projected into the classroom. Students were provided with a list of questions centered around discovering the older adult's childhood, young adult years, family, and current hobbies and activities to assist with discussion. This allowed students to gain an understanding of how people age physically, psychologically, and socially from a real-life perspective.

Students worked in groups and created an interactive lecture that they could teach the older adults. This was set up as a virtual classroom experience. An example of a lecture would be "simple ways to increase your strength at home". Students created a team lesson incorporating strength training demonstrations using cans, plastic juice or water bottles, or laundry detergent containers. The students could demonstrate and participants could follow along at their site. This type of lesson had some type of didactic information that could be presented to the older adults. This would be a mechanism for students to have a service-learning experience with older adults. 


\subsection{Sample Population \& Survey}

A total of 132 junior-level Health Behavior Science undergraduate students completed a pre- and post-questionnaire that assessed aging knowledge and perceptions. The majority of the participants were female (82\%) and Caucasian (81\%). The pre-questionnaire was given to the students the first day of the course and the post-questionnaire was given the last week of the course. The questionnaire included a modified 10-item true/false Facts on Aging quiz (Breytspraak \& Badura, 2015) followed by several open-ended questions that included: What is aging? What is a senior center? What type of life does someone over the age of 65 live? What are descriptors of someone over the age of 65 ? The post-questionnaire included all of the items from the pre-questionnaire with the addition of: what class activities changed their perception of aging.

\subsection{Analysis}

In order to test the change in students' knowledge on aging, a dependent paired samples t-test was used to examine changes in aging knowledge pre- to post-course. Knowledge of aging was measured via a modified version of the Facts on Aging quiz (Breytspraak \& Badura, 2015). The authors modified this to 10 items, and then calculated a score based on the number of correct items. This was then transposed into a percentage score of correct responses.

A thematic analysis was conducted to examine students' descriptors (10) of individuals over the age of 65 both pre- and post-course. After examining the verbatim responses in Excel, each interview was coded by hand according to coding methods by Strauss \& Corbin (1990) until saturation was reached. Key words were attached to the responses according to processes outlined by Miles \& Huberman (1994) and coding proceeded until saturation was reached (Miles \& Huberman, 1994). After the initial code list was finalized by the graduate student, the primary investigator (PI) evaluated the codes from the survey using the check-coding method with the list of codes, their categories, and definitions (Miles \& Huberman, 1994: p. 64). After refining the categories for the codes, the graduate student and PI blindly clustered the organized codes in order to determine overarching themes (Miles \& Huberman, 1994).

\section{Results}

The results of a thematic analysis of the descriptors of adults 65 and over indicated the following themes: fragile or weak, positive personality traits, memory loss, senses decline, wise, aging skin, retired, grandparent, height decline, senior, health problems, tired, and negative personality traits. A detailed presentation of these themes is reported in Figure 1.

Prior to course start, students used predominantly negative descriptors of older adults and the aging process (see Table 1). There were a total of 1386 descriptors that the students used to describe adults 65 and over at the start of the semester. Students described this population as fragile (104 descriptors or 7.5\%), 
Fragile or weak: fragile, weak, frail, brittle bones, low bone density, muscle decline, decline in coordination, limited range of motion, mobility or flexibility issues, walker, cane

Positive personality traits: patient, loving, caring, honest, happy, friendly, thoughtful, giving, genuine, generous, gentle, helpful, welcoming, truthful, thankful, down to earth, sociable, healthy, active, strong, capable, independent, nostalgic, reminiscent, spiritual

Memory loss: memory loss, forgetful, brain decline, Alzheimer's, senile, no filter when speaking, not all there, harder to learn new things

Senses decline: glasses, loss of eyesight, loss of hearing, hearing aid, loss of senses, dentures

Wise: wise, mature, experienced, knowledgeable, smart

Aging skin: wrinkles, saggy skin, changes in skin

Retired: retired, relaxed, financially well off, vacations, move to Florida, AARP, life insurance

Grandparent: grandparent, family-oriented

Height decline: short, shrinking, height decline, posture

Senior: senior, senior citizen, old

Health problems: health problems, dependent, limited

Tired: tired, fatigued, problems sleeping

Negative personality traits: sad, scared, grumpy, impatient, short fused, traditional, set in their ways

Hobbies: hobbies, travel, free time, golf

Figure 1. Descriptor themes.

Table 1. Frequency of pre and post descriptors.

\begin{tabular}{|c|c|c|}
\hline Descriptors & Pre F (\%) & Post F (\%) \\
\hline Fragile or weak & $104(7.5)$ & $45(5.3)$ \\
\hline Gray, white, thinning, or balding hair & $83(6.0)$ & $63(7.5)$ \\
\hline Positive personality traits & $160(11.5)$ & $268(31.8)$ \\
\hline Memory loss & $76(5.5)$ & $17(2.0)$ \\
\hline Senses decline & $84(6.1)$ & $66(7.8)$ \\
\hline Slower & $67(4.8)$ & $21(2.5)$ \\
\hline Wise & $137(9.9)$ & $87(10.3)$ \\
\hline Aging skin & $72(5.2)$ & $71(8.4)$ \\
\hline Retired & $81(5.8)$ & $37(4.4)$ \\
\hline Sedentary or inactive & $63(4.6)$ & $4(0.5)$ \\
\hline Grandparent & $34(2.5)$ & $34(4.0)$ \\
\hline Height decline & $37(2.7)$ & $21(2.5)$ \\
\hline Senior & $99(7.1)$ & $20(2.4)$ \\
\hline Health problems & $134(9.7)$ & $38(4.5)$ \\
\hline Tired & $31(2.2)$ & $7(0.8)$ \\
\hline Negative personality traits & $113(8.2)$ & $28(3.3)$ \\
\hline Hobbies & $11(0.8)$ & $16(1.2)$ \\
\hline Total & 1386 & 843 \\
\hline
\end{tabular}

gray, white, thinning or bald hair (83 descriptors or $6.0 \%$ ), memory loss (76 descriptors or 5.5\%), decline in senses (84 descriptors or 6.1\%), slower (67 descriptors or $4.8 \%$ ), sedentary or inactive (63 descriptors or $4.6 \%$ ), decline in height (37 descriptors or $2.7 \%$ ), senior (99 descriptors or $7.1 \%$ ), with health 
problems (134 descriptors or 9.7\%), tired (31 descriptors or 2.2\%), and with negative personality traits (113 descriptors or $8.2 \%)$. However, the students did report some positive descriptors of older adults and aging with 160 (11.5\%) descriptors as positive personality traits, $137(9.9 \%)$ as wise, and $81(5.8 \%)$ descriptors related to retired.

Following completion of the health and aging course, the students had fewer negative descriptors of older adults. Post-course completion, there were 843 total descriptors with $45(5.3 \%)$ related to fragile, $63(7.5 \%)$ as gray, white, thinning or balding, $17(2.0 \%)$ as having memory loss, $66(7.7 \%)$ with senses decline, 21 $(2.5 \%)$ as slower, $4(0.5 \%)$ as sedentary or inactive, $21(2.6 \%)$ as height decline, $20(2.4 \%)$ described as senior, 38 (4.5\%) words related to health problems, 7 $(0.8 \%)$ as tired, and $28(3.3 \%)$ with negative personality traits.

Similarly, the positive personality trait descriptors increased from $160(11.5 \%)$ initially, to 268 (31.8\%) following course completion. There were a few descriptors that remained largely unchanged from pre- to post-assessment. The following descriptor themes changed: aging skin: pre: $72(5.2 \%)$ to post: $71(8.4 \%)$; grandparent: pre: $34(2.5 \%)$ to post: $34(4.0 \%)$; hobbies: pre: $11(0.8 \%)$ to post: 16 (1.2\%), wise: pre: 137 (9.9\%) to post: 87 (10.3\%); retired: pre: $81(5.8 \%)$ to post: $37(4.4 \%)$.

In addition, the independent samples paired t test showed a significant increase $(p<0.0001)$ in aging knowledge scores from the beginning of the class to the end of the class for both years of this project and for overall (see Table 2). In year one, the scores increased from $64.45(+12.63)$ to $78.66(+12.67)$ and in year two, the scores increased from $69.41(+13.12)$ to $80.75(+11.07)$.

\section{Discussion}

Overall, the results of this study indicated that an undergraduate health and aging course may change undergraduate students' perceptions of older adults and aging to be more positive. Prior to course start, students were asked to provide 10 descriptors of adults 65 and older. At course end, students were asked to do the same. However, due to semester fatigue, many of the students listed less than 10 descriptors of adults 65 and older. Nonetheless, their responses indicated that students' perceptions changed from predominantly viewing older adults as fragile, weak, inactive, senile, and impatient, with many health problems, to viewing them as more capable, welcoming, patient, kind, happy, and active individuals.

Table 2. Paired T test of pre and post knowledge scores.

\begin{tabular}{|c|c|c|c|c|c|c|c|c|}
\hline \multirow[t]{2}{*}{ Cohort } & \multirow[t]{2}{*}{ Mean } & \multirow{2}{*}{ Std. Deviation } & \multirow{2}{*}{ Std. Error Mean } & \multicolumn{2}{|c|}{$\begin{array}{l}95 \% \text { Confidence } \\
\text { Interval of the Difference }\end{array}$} & \multirow[t]{2}{*}{$\mathbf{t}$} & \multirow[t]{2}{*}{$\mathrm{df}$} & \multirow{2}{*}{ Sig. (2-tailed) } \\
\hline & & & & Lower & Upper & & & \\
\hline 2017 & -14.212 & 13.668 & 1.474 & -17.143 & -11.282 & -9.643 & 85 & 0.0001 \\
\hline 2018 & -11.337 & 14.264 & 2.103 & -15.573 & -7.101 & -5.391 & 45 & 0.0001 \\
\hline Total & -13.210 & 13.892 & 1.209 & -15.602 & -10.818 & -10.925 & 131 & 0.0001 \\
\hline
\end{tabular}


In this study, many undergraduate students indicated that they viewed older adults as loving, caring, friendly, etc. prior to course start, however, students used these descriptors even more frequently following the course. It is also important to note that many of the students perceived older adults as wise, mature, and experienced individuals prior to course start, and that the frequency of these descriptors remained the same following the course.

Furthermore, the students' knowledge of aging increased over the course of the semester. Students initially answered about $65 \%$ of the aging questions correctly, and then after course completion answered about $80 \%$ of the questions correctly. Some of these questions pertained to perceptions of physical, mental, and social aging (e.g. "The majority of older adults have Alzheimer's disease", "Physical strength declines with old age", and "All five senses tend to decline with age"). Similar to previous literature (Kimuna, Knox, \& Zusman, 2005; Mosher-Ashley \& Ball, 1999), the students in this course initially grouped older adults together as having physical problems and lacking physical strength. However, these negative ideas about aging improved by the end of the semester.

In addition, these findings add to the current body of literature surrounding the positive impact that intergenerational service-learning programs have on students' perceptions of older adults (Knapp \& Stubblefield, 2000). The results of this study are consistent with the literature that intergenerational service-learning reduces negative perceptions of older adults and promotes a better understanding of the aging process among undergraduate students (O'Hanlon \& Brookover, 2002; Knapp \& Stubblefield, 2000). Similar to Vandersberger et al. and Darling's findings, students were initially hesitant and resistant to engage in the service-learning projects, however, as they began developing relationships with the older adults, their perceptions became more positive (Darling, 2016; Vandersberger \& Wakefield, 2008).

Additionally, the intergenerational service-learning component of this study provided the students with the opportunity to have "meaningful experiences" with the older adults. Our findings were consistent with the current body of literature that meaningful interactions reduce the prevalence of negative perceptions of older adults among undergraduate students (Kalisch et al., 2013). The students were required to volunteer their time at a senior center for 2 - 3 hours throughout the semester. Many of the students had the opportunity to volunteer at a "senior prom" that one of the local senior centers hosted. The students volunteered as line-dance instructors, servers, greeters, and photo-booth attendants. Other students volunteered for special bingo (e.g.: St. Patrick's Day Bingo), bake sales, and flea market events at the senior centers.

Similar to Whitbourne and colleagues' findings, many of the students were hesitant to engage in the volunteer activities at the beginning of the course, however, these activities became some of the most memorable experiences for the undergraduate students (Whitbourne, Collins, \& Skultety, 2001). The students began to have more positive perceptions which may have stemmed from their engagement with the older adults. Similarly, students were required to par- 
ticipate in an exercise class for older adults that was hosted by a local senior center or YMCA. Many of the students indicated that the exercise classes were the most highlighted experiences of the health and aging course. It is possible that this course requirement greatly changed the students' perceptions that older adults' lives are boring and inactive. One of the students indicated that "all the activities that they (older adults) do would leave me exhausted by the end of the day".

Likewise, the students had the opportunity to talk to some of the older adults from the local senior center via FaceTime or Zoom over the course of the semester. The students indicated that this was one of their favorite class activities and one that increased their understanding of older adults the most. Additionally, the students engaged in sensory impairment activities that helped them understand what it is like to lose one's senses as they age. For example, students were asked to eat a jellybean while holding their nose to mimic losing their sense of taste as an in-class activity. Out of class, students were instructed to use earplugs for several hours to simulate hearing loss while completing their daily activities such as going to an eating establishment, shopping, or spending time with their friends. Many of the students indicated that this activity greatly impacted them, and as a result, they intended to be more empathetic to the older adults in their lives.

In addition, many of the students themselves recognized that their perceptions were changed as a result of the knowledge and experiences they had gained over the course of the semester. Below are some examples of students' comments regarding how their perceptions changed.

- "This course greatly impacted my perception of aging. You can be older and still very much active. I used to think when you age, you can't do anything, which I know now is not the case."

- "We need to be more accepting and patient with the older community."

- "My impression changed for the better. I learned that aging is more than getting gray hair. Older adults can still live a happy and satisfied life."

- "I have come to realize that many adults are still physically fit, socially active, and mentally sharp. Their age does not define them and it is not a limit. The fitness class and service-learning experience changed this perception.”

\subsection{Future Directions}

Future research should attempt to provide intergenerational interactions early on with youth and older adults, thereby having positive experiences to thwart the development of negative aging perceptions. Evidence of these types of interactions can be seen in multi-use buildings which house nursing homes and day cares, with elementary school pen pal programs, and mentoring programs that connect older adults and school age children. Future research could capitalize on these intergenerational interactions and explore the perceptions of these youth engaged with older adults compared to those with limited exposure to the aging population. 


\subsection{Conclusion}

Overall, this study has demonstrated that an undergraduate health and aging course with a service-learning component impacted undergraduate student's perceptions of older adults and aging to be more positive. This study adds to the current body of literature as we conducted a thematic analysis of undergraduate students' verbatim descriptions of older adults AND how their actual words describing older adults changed to be more positive over the course of the semester. With the continued growth in the aging population and the need to interact with older adults in society, it is important to determine methods to form positive perceptions of the aging population. The aging population is with us always and should be embraced.

\section{Conflicts of Interest}

The authors declare no conflicts of interest regarding the publication of this paper.

\section{References}

Bales, S. S., Eklund, S. J., \& Siffin, C. F. (2000). Children's Perceptions of Elders before and after a School Based Intergenerational Program. Educational Gerontology, 31, 677-689. https://doi.org/10.1080/03601270050200662

Bodner, E. (2009). On the Origins of Ageism among Older and Younger Adults. International Psychogeriatrics, 21, 1003-1014. https://doi.org/10.1017/S104161020999055X

Breytspraak, L., \& Badura, L. (2015). Facts on Aging Quiz (Revised; Based on Palmore (1977; 1981)). Unpublished Instrument. http://info.umkc.edu/aging/quiz

Butler, R. N. (1980). Ageism: A Foreword. Journal of Social Issues, 36, 8-11. https://doi.org/10.1111/j.1540-4560.1980.tb02018.x

Cohen, H. L., Sandel, M. H., Thomas, C. L., \& Barton, T. R. (2004). Using Focus Groups as an Educational Methodology: Deconstructing Stereotypes and Social Work Practice Misconceptions Concerning Aging and Older Adults. Educational Gerontology, 30, 329-346. https://doi.org/10.1080/03601270490278858

Darling, R. M. (2016). Knowledge of Aging and Attitudes toward Older People by Communication Sciences and Disorders Students. Contemporary Issues in Communication Science and Disorders, 43, 50-63. https://doi.org/10.1044/cicsd_43_S_50

Fair, C. D., \& Delaplane, E. (2015). "It Is Good to Spend Time with Older Adults. You Can Teach Them, They Can Teach You": Second Grade Students Reflect on Intergenerational Service Learning. Early Childhood Education Journal, 43, 19-26.

https://doi.org/10.1007/s10643-014-0634-9

Feenstra, A. (2012). Student Attitudes toward Older Adults. Honors Theses. 1776. https://scholarworks.wmich.edu/honors_theses/1776

Fiske, S. T., Cuddy, A. J. C., Glick, P., \& Xu, J. (2002). A Model of (Often Mixed) Stereotype Content: Competence and Warmth Respectively Follow from Perceived Status and Competition. Journal of Personality and Social Psychology, 82, 878-902.

https://doi.org/10.1037/0022-3514.82.6.878

Gellis, Z. D., Sherman, S., \& Lawrance, F. (2003). First Year Graduate Social Work Students' Knowledge of and Attitude toward Older Adults. Educational Gerontology, 29, 1-16. https://doi.org/10.1080/713844235 
Happel, B., \& Brooker, J. (2001). Who Will Look after My Grandmother? Attitudes of Student Nurses toward the Care of Older Adults: Gerontology Is an Unpopular Area of Study among Australian Nursing Students. Journal of Gerontological Nursing, 27, 12-17. https://doi.org/10.3928/0098-9134-20011201-07

Henderson, J., Xiao, L., Siegloff, L., Kelton, M., \& Paterson, J. (2008). Older People Have Lived Their Lives: First Year Nursing Students' Attitudes towards Older People. Contemporary Nurse, 30, 32-45. https://doi.org/10.5172/conu.673.30.1.32

Kalisch, H. R., Coughlin, D. R., Ballard, S. M., \& Lamson, A. (2013). Old Age Is a Part of Living: Student Reflections on Intergenerational Service-Learning. Gerontology \& Geriatrics Education, 34, 99-113. https://doi.org/10.1080/02701960.2012.753440

Kimuna, S. R., Knox, D., \& Zusman, M. (2005). College Students' Perceptions about Older People and Aging. Educational Gerontology, 31, 563-572. https://doi.org/10.1080/03601270590962514

Knapp, J. L., \& Stubblefield, P. (2000). Changing Students' Perceptions of Aging: The Impact of an Intergenerational Service-Learning Course. Educational Gerontology, 26, 611-621. https://doi.org/10.1080/03601270050200617

McHugh, K. E. (2003). Three Faces of Ageism: Society, Image and Place. Ageing \& Society, 23, 165-185. https://doi.org/10.1017/S0144686X02001113

Mendonca, J., Marques, S., \& Abrams, D. (2018). Children's Attitudes toward Older People: Current and Future Directions. In Contemporary Perspectives on Ageism (pp. 517-548). Cham: Springer. https://doi.org/10.1007/978-3-319-73820-8_30

Miles, M., \& Huberman, M. (1994). Qualitative Data Analysis: An Expanded Sourcebook. Thousand Oaks, CA: SAGE Publications, Inc.

Mosher-Ashley, P. M., \& Ball, P. (1999). Attitudes of College Students toward Elderly Persons and Their Perceptions of Themselves at Age 75. Educational Gerontology, 25, 89-102. https://doi.org/10.1080/036012799268034

Newman, S., Ward, C. R., Smith, T. B., Wilson, J. O., \& McCrea, J. M. (1997). Intergenerational Programs: Past, Present, and Future. New York: Routledge.

O’Hanlon, A. M., \& Brookover, B. C. (2002). Assessing Changes in Attitudes about Aging: Personal Reflections and a Standardized Measure. Educational Gerontology, 28, 711-725. https://doi.org/10.1080/03601270290099732

O'Hanlon, A. M., \& Brookover, B. C. (2002). Assessing Changes in Attitudes about Aging: Personal Reflections and a Standardized Measure. Educational Gerontology, 28, 711-725. https://doi.org/10.1080/03601270290099732

Obhi, H. K., \& Woodhead, E. L. (2016). Attitudes and Experiences with Older Adults: A Case for Service Learning for Undergraduates. Gerontology \& Geriatrics Education, 37, 108-122. https://doi.org/10.1080/02701960.2015.1079704

Schwartz, L. K., \& Simmons, J. P. (2001). Contact Quality and Attitudes toward the Elderly. Educational Gerontology, 27, 127-137. https://doi.org/10.1080/03601270151075525

Strauss, A., \& Corbin, J. (1990). Grounded Theory Research: Procedures, Canons, and Evaluative Criteria. Qualitative Sociology, 13, 1. https://doi.org/10.1007/BF00988593

Sweetland, J., Volmert, A., \& O'Neil, M. (2017). Finding the Frame: An Empirical Approach to Reframing Aging and Ageism. Washington DC: FrameWorks Institute.

Vandersberger, E., \& Wakefield, M. (2008). Service Learning with Rural Older Adults. Journal of Intergenerational Relationships, 3, 83-97.

https://doi.org/10.1300/J194v03n04_06

Vespa, J., Armstrong, D. M., \& Medina, L. (2018). Demographic Turning Points for the 
United States: Population Projections for 2020 to 2060. Washington DC: US Department of Commerce, Economics and Statistics Administration, US Census Bureau.

Vickers, K. (2007). Aging and the Media: Yesterday, Today, and Tomorrow. Journal of Health Promotion, 5, 100-105. https://doi.org/10.32398/cjhp.v5i3.1256

Whitbourne, K., Collins, K. J., \& Skultety, K. M. (2001). Formative Reflections on Service-Learning in a Course on the Psychology of Aging. Educational Gerontology, 7, 105-115. https://doi.org/10.1080/036012701750069076

Wurtele, S. K. (2009). “Activities of Older Adults” Survey: Tapping into Student Views of the Elderly. Educational Gerontology, 35, 1026-1031.

https://doi.org/10.1080/03601270902973557 